\title{
Feasibility and Safety of Laparoscopic Gallbladder Resection for Gallbladder Tumours
}

\author{
HAJIME IMAMURA, TOMOHIKO ADACHI, TAKAYUKI TANAKA, HAJIME MATSUSHIMA, \\ TAKANOBU HARA, AKIHIKO SOYAMA, MASAAKI HIDAKA and SUSUMU EGUCHI
}

Department of Surgery, Nagasaki University Graduate School of Biomedical Sciences, Nagasaki, Japan

\begin{abstract}
Background/Aim: The laparoscopic approach is not widely used for gallbladder tumours because of the high degree of malignancy associated with gallbladder cancer and technical difficulties. This study aimed to clarify the feasibility and safety of laparoscopic gallbladder resection for gallbladder tumours. Patients and Methods: This retrospective study enrolled patients who underwent laparoscopic wholelayer cholecystectomy or laparoscopic gallbladder bed resection for gallbladder tumours between April 2010 and December 2020. We analysed the perioperative and oncological outcomes of patients with gallbladder carcinoma. Results: The cohort comprised 31 patients, including 13 who underwent laparoscopic whole-layer cholecystectomy and 18 who underwent laparoscopic gallbladder bed resection. Twenty patients were diagnosed with gallbladder cancer. Three patients $(15 \%)$ had metastases in harvested lymph nodes. No postoperative complications were observed. Recurrence occurred in four patients; the primary location was the liver in three patients and lymph node in two. The 1-, 3-, and 5-year recurrence-free survival and overall survival rates were $87 \%$, $78.3 \%$, and $58.8 \%$, and $100 \%, 70.5 \%$, and $70.5 \%$, respectively. Conclusion: Our surgical strategy enables safe and curative gallbladder resection for gallbladder tumours, without excess or insufficient resection.
\end{abstract}

Laparoscopic cholecystectomy (LC) is well recognized as a standard procedure for benign gallbladder disease. However, the Japanese Society of Hepato-Biliary-Pancreatic Surgery

This article is freely accessible online.

Correspondence to: Susumu Eguchi, MD, Ph.D., Department of Surgery, Nagasaki University Graduate School of Biomedical Sciences, 1-7-1 Sakamoto, Nagasaki 852-8501, Japan. Tel: +81 958197316, Fax: +81 958197319, e-mail: sueguchi@nagasaki-u.ac.jp

Key Words: Gallbladder cancer, laparoscopic whole-layer cholecystectomy, laparoscopic gallbladder bed resection, radical cholecystectomy. currently strongly recommends open cholecystectomy for suspected gallbladder cancer (1). Gallbladder tumours range from benign gallbladder disease to advanced gallbladder cancer. In Japan, the laparoscopic approach has not been widely used for gallbladder tumours because of the high level of malignancy associated with gallbladder cancer and procedural technical difficulties.

Previous studies have reported that LC for gallbladder cancer may worsen the long-term surgical outcome due to incomplete excision (2), bile spillage induced by intraoperative gallbladder injury $(3,4)$, or port site recurrence $(5,6)$. In addition, it is difficult to accurately diagnose the type of gallbladder tumour and depth of invasion preoperatively (7, $8)$. In the treatment of gallbladder tumours, these clinical issues must be addressed to obtain radical resection without excess or insufficient tissue removal.

With the rapid technical improvements and instrument advances since the publication of the abovementioned studies, the indication of LC has tended to expand, and is even used in patients with suspected gallbladder cancer (9-13). However, there is currently no consensus between institutions regarding the optimal surgical management and oncological outcomes for patients with gallbladder tumours. At our Institution, we have been performing gallbladder resection and lymph node harvesting for gallbladder tumours that are potential carcinomas of the muscularis propria/subserosa (SS) in patients without definite lymph node enlargement since April 2010. We believe that the laparoscopic approach for gallbladder tumours should be re-evaluated in the current clinical environment.

The purpose of this study was to clarify the feasibility and safety of laparoscopic gallbladder resection for gallbladder tumours.

\section{Patients and Methods}

Since April 2010, we have used the laparoscopic approach to remove gallbladder tumours when possible. We investigated patients who underwent laparoscopic whole-layer cholecystectomy (LWLC) or laparoscopic gallbladder bed resection (LGBR) for removal of gallbladder tumour in our Department between April 2010 and December 2020. We retrospectively analysed the characteristics, 
perioperative outcomes, pathological findings, and oncological outcomes of patients diagnosed with gallbladder carcinoma.

Laparoscopic surgery was indicated for polypoid lesions larger than $10 \mathrm{~mm}$, wall-thickening lesions, and suspected $\mathrm{T} 1$ or T2 gallbladder carcinomas. We preoperatively diagnosed the type of gallbladder tumour using imaging modalities such as ultrasonography, dynamic computed tomography, endoscopic ultrasonography, and enhanced magnetic resonance imaging. In all patients, the final diagnosis was confirmed by pathological examination of resected specimens.

This study was conducted in accordance with the Declaration of Helsinki and the ethical guidelines for clinical studies of the Ministry of Health, Labour, and Welfare of Japan. The study protocol was approved by the Ethics Committee of Nagasaki University Hospital (approval no. 19102143)

Operative strategy for gallbladder tumours. Our operative strategy for gallbladder tumours is shown in Figure 1. The location of the tumour was identified using laparoscopic intraoperative ultrasonography. When the tumour was on the peritoneal side, we performed LWLC; when the tumour was on the hepatic side, we performed LGBR to achieve negative surgical margins Intraoperatively, we checked the stump of the cystic duct and harvested the lymph nodes in the hepatoduodenal ligament for frozen section diagnosis. When malignant findings were detected, the extrahepatic bile duct was removed and D2 lymphadenectomy was performed under laparotomy. In Japan, D2 lymphadenectomy is defined as removal of the lymph nodes in the hepatoduodenal ligament, around the common hepatic artery, and around the posterosuperior region of the pancreatic head. When there were no malignant findings, laparoscopic surgery was continued without conversion to laparotomy.

Surgical procedure of $L W L C$. The port placement was the same as for LC. A 12-mm trocar was placed at the umbilicus for the scope, a 12$\mathrm{mm}$ trocar was placed in the epigastric region, and two 5-mm trocars were placed in the right subcostal region. We performed peritoneal lavage cytology and then checked the location of the tumour using intraoperative ultrasonography. After exposing the cystic duct and cystic artery, we removed the stump of the cystic duct for frozen section diagnosis. The lymph nodes in the hepatoduodenal ligament were then harvested and submitted for frozen section diagnosis. After confirming that the frozen sections were pathologically negative, we started LWLC from the fundus of the gallbladder. The whole-layer gallbladder wall, including the cystic plate, was easily detached from the liver bed using blunt dissection. The resected specimen was put in a retrieval bag and removed through the umbilical port. A drain was usually unnecessary.

Surgical procedure of LGBR. Port replacement, peritoneal lavage cytology, and intraoperative ultrasonography were performed as described above. When the tumour was on the hepatic side, LGBR was selected. After exposing the cystic duct and cystic artery, we collected the stump of the cystic duct for frozen section diagnosis. The lymph nodes in the hepatoduodenal ligament were then harvested and submitted for frozen section diagnosis. After confirming that the frozen sections were pathologically negative, we started LGBR under the Pringle manoeuvre. An ultrasonically activated device was used during liver parenchymal transection. The resection line of the liver was $10 \mathrm{~mm}$ from the gallbladder bed to ensure negative surgical margins. After completion of the liver bed resection and lymph node harvesting, the common bile duct and proper hepatic artery were exposed (Figure 2). The resected specimen was put in a retrieval bag and removed through the umbilical port. A drain was placed through the foramen of Winslow.

Statistical analysis. Continuous variables are expressed as the median values with ranges. Overall survival (OS) was defined as the interval from surgery to death or final follow-up. All patients were followed up until death or February 2021. Recurrence-free survival (RFS) was defined as the interval from surgery to the first recurrence or final follow-up. OS and RFS curves were calculated using the Kaplan-Meier method. All statistical analyses were performed with EZR (Saitama Medical Center, Jichi Medical University) (14)

Compliance with ethical requirements. All procedures were in accordance with the ethical standards of the responsible committee on human experimentation (institutional and national) and the Helsinki Declaration of 1975, revised in 2008. Informed consent was obtained from all included patients.

\section{Results}

Lesions other than gallbladder cancer. A total of 31 patients underwent resection of gallbladder tumour during the study period, including 13 who underwent LWLC and 18 who underwent LGBR. Of the 31 patients, 11 (35\%) were postoperatively diagnosed with conditions other than gallbladder cancer; the lesion in these patients was adenomyomatosis in three, chronic cholecystitis in three, adenoma in two, polyp in two, and metastatic renal cell carcinoma in one.

Characteristics and surgical outcome of patients who underwent gallbladder resection for gallbladder cancer. The characteristics and surgical outcomes of the 20 patients diagnosed with gallbladder cancer are summarized in Table I. The tumour was on the peritoneal side in six patients and the hepatic side in 14. The median tumour size was $27 \mathrm{~mm}$ (range $=12-40 \mathrm{~mm})$. In three patients $(15 \%)$, metastases were detected in harvested lymph nodes by frozen section diagnosis. No postoperative complications of Clavien-Dindo grade $3 \mathrm{a}$ or above were observed, and the median postoperative hospital stay was 11 days (range $=5-14$ days).

Final pathological diagnosis and outcome of gallbladder cancer. The data of the patients pathologically diagnosed with gallbladder cancer are shown in Table II. Three patients with SS invasion (case no. 14, 18, and 19) required conversion to laparotomy because the intraoperative pathological diagnosis was positive (lymph node in all three cases). R0 resection was achieved in all patients. Recurrence was observed in four patients; the depth was SS and the primary location of recurrence was the liver in three patients (case no. 17, 19, and 20, no recurrence in segment 4a/5) and 


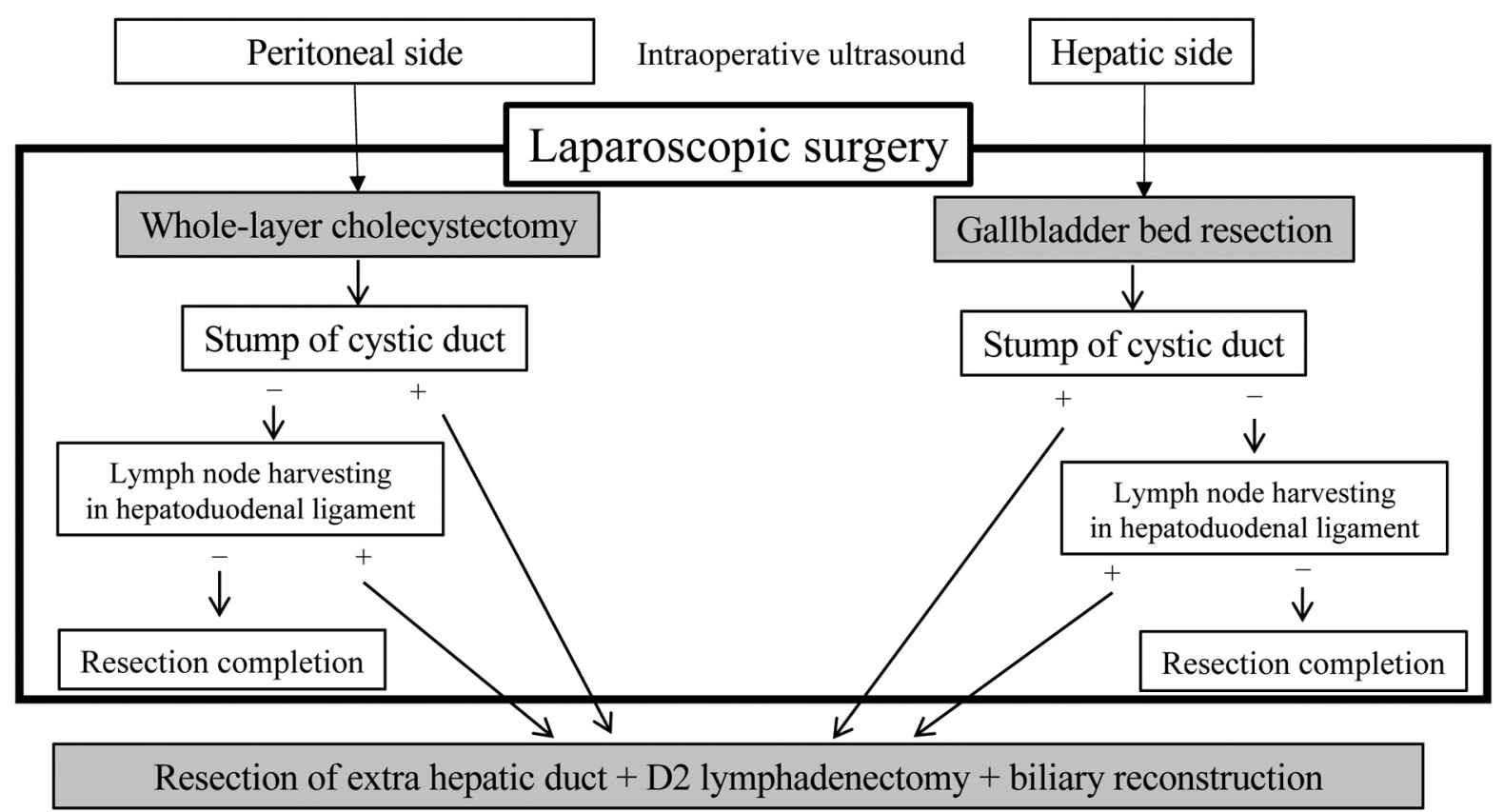

Figure 1. Operative strategy for gallbladder tumours.

lymph nodes in two (case no. 18, 19). No port site recurrence or peritoneal dissemination was detected. The long-term outcomes of patients with gallbladder carcinoma are shown in Figure 3. The 1-, 3-, and 5-year RFS rates were $87 \%$, $78.3 \%$ and $58.8 \%$, respectively. The 1-, 3-, and 5-year OS rates were $100 \%, 70.5 \%$ and $70.5 \%$, respectively.

\section{Discussion}

This study investigated the feasibility and safety of laparoscopic gallbladder resection for gallbladder tumours. Our study revealed that it was difficult to obtain an accurate preoperative diagnosis for gallbladder tumours. In all cases, our surgical strategy allowed us to complete safe and curative minimally invasive surgery without excess or insufficient resection.

In the clinical setting, there are discrepancies between the preoperative diagnosis and the postoperative pathological diagnosis regarding the depth of invasion and the distinction between benign and malignant. Gallbladder cancer is a differential diagnosis for polypoid lesions that are larger than $10 \mathrm{~mm}$, sessile, or rapidly growing (15-17), while adenomyomatosis and chronic cholecystitis are important differential diagnoses for gallbladder carcinoma that may be difficult to diagnose preoperatively (18-20). In our series, out of the 11 patients diagnosed with diseases other than gallbladder cancer, six (55\%) were diagnosed with adenomyomatosis and chronic cholecystitis. With the advent of endoscopic ultrasonography, the diagnostic accuracy for depth of tumour invasion has been improved by its use in combination with other modalities (18), although the qualitative diagnosis of tumours is still difficult. The Japanese Society of Hepato-Biliary-Pancreatic Surgery strongly recommends open cholecystectomy for suspected gallbladder cancer (1). However, a reasonable number of suspected gallbladder cancer cases are eventually diagnosed as benign lesions, and it is important to avoid overly invasive surgical strategies for benign lesions. The laparoscopic approach may avoid unnecessarily invasive surgery for gallbladder tumours.

Our surgical strategy was based on achieving R0 resection. The three important steps to success for our operative strategy for gallbladder tumours without excess or insufficient resection are: (i) Re-evaluation of the precise tumour location using intraoperative ultrasonography to select the surgical procedure (LWLC or LGBR); (ii) pathological diagnosis of the cystic duct stump and harvested lymph nodes by intraoperative frozen section examination; and (iii) appropriate resection to secure negative margins.

With the limitations of accurate preoperative diagnosis, intraoperative re-evaluation of the tumour location is mandatory for the final selection of the surgical procedure. Following appropriate indications for LWLC and LGBR avoids exposure of the tumour and achieves $\mathrm{R} 0$ resection. Intraoperative examination of frozen sections is also crucial in deciding whether to resect the extrahepatic duct and perform D2 lymphadenectomy and biliary reconstruction. 


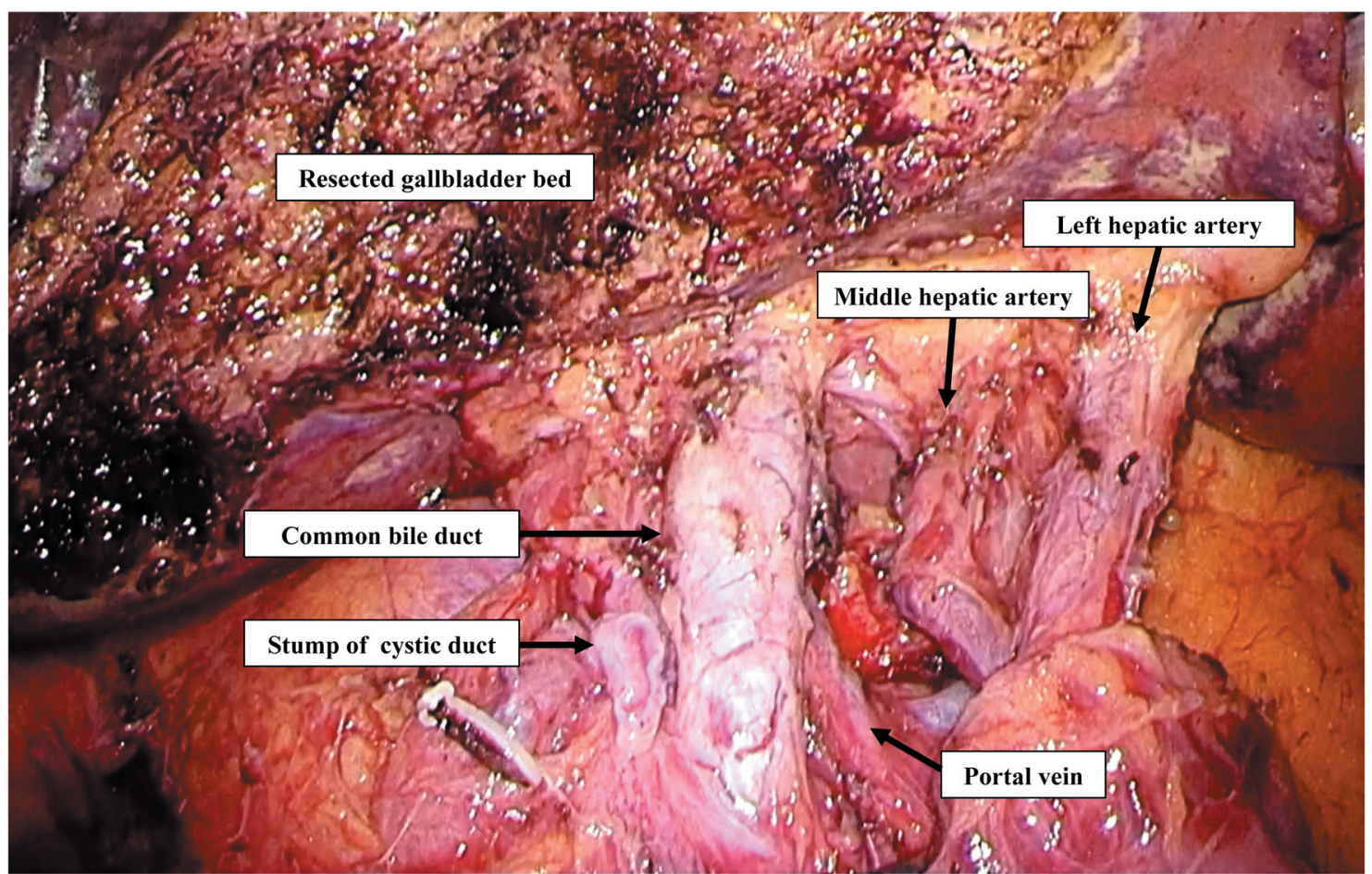

Figure 2. Surgical procedure for laparoscopic gallbladder resection. After the completion of gallbladder bed resection and lymph node harvesting, the common bile duct and proper hepatic artery are exposed.

Patients with a positive surgical margin of the cystic duct specimen require resection of the extrahepatic duct for R0 resection. In addition, lymphatic infiltration around the bile duct is the main route of tumour spread (19), and distant microscopic spread separate from the primary tumour is sometimes detected (20). Therefore, extrahepatic bile duct resection increases the curative resection rate in patients with cancer invading the gallbladder neck $(21,22)$, those with lymph node metastasis $(7,21)$, or those with cancer associated with perineural invasion (23). We perform resection of the extrahepatic duct by laparotomy not only to achieve $\mathrm{R} 0$ resection, but also to perform appropriate lymph node dissection when the harvested lymph nodes are positive. In our series, three patients had positive lymph nodes and were converted to laparotomy. Two patients had distant recurrences during the observation period, although it was considered that local control was obtained by resection of the extrahepatic duct and D2 lymphadenectomy.

Regarding the appropriate performance of tumour resection to secure safe margins, the techniques of LWLC and LGBR have already been established $(2,10,24,25)$. The entire SS layer is removed by LWLC, theoretically achieving complete resection of $\mathrm{T} 1$ or $\mathrm{T} 2$ gallbladder cancer. In contrast, the optimal extent of liver resection between wedge resection and resection of segments $4 \mathrm{~b}$ and 5 remains
Table I. Patient and perioperative characteristics ( $n=20$; peritoneal side 6/hepatic side 14).

\begin{tabular}{|c|c|}
\hline Characteristic & Value \\
\hline \multicolumn{2}{|l|}{ Age, years } \\
\hline Median (range) & $74(56-87)$ \\
\hline \multicolumn{2}{|l|}{ Gender, n (\%) } \\
\hline Male:female & $8: 12$ \\
\hline \multicolumn{2}{|l|}{ Tumour diameter, $\mathrm{mm}$} \\
\hline Median (range) & $27(12-40)$ \\
\hline \multicolumn{2}{|l|}{ Gross type, $\mathrm{n}$} \\
\hline Pedunculated $v s$. sessile & $4: 16$ \\
\hline \multicolumn{2}{|c|}{ Intraoperative pathological diagnosis } \\
\hline Positive & $3(15 \%)$ \\
\hline \multicolumn{2}{|l|}{ Positive site, $\mathrm{n}$} \\
\hline Cystic duct: lymph node & $0: 3$ \\
\hline \multicolumn{2}{|l|}{$\begin{array}{l}\text { Number of intraoperative } \\
\text { dissected lymph nodes }\end{array}$} \\
\hline Median (range) & $2(0-11)$ \\
\hline \multicolumn{2}{|l|}{ Operative time, $\min$} \\
\hline Median (range) & $207(109-332)$ \\
\hline \multicolumn{2}{|l|}{ Blood loss, g } \\
\hline Median (range) & $50(1-670)$ \\
\hline \multicolumn{2}{|l|}{ Complications, n (\%) } \\
\hline Clavien-Dindo $\geq 3 \mathrm{a}$ & 0 \\
\hline \multicolumn{2}{|c|}{ Postoperative hospital stay, days } \\
\hline Median (range) & $11(5-14)$ \\
\hline
\end{tabular}


A

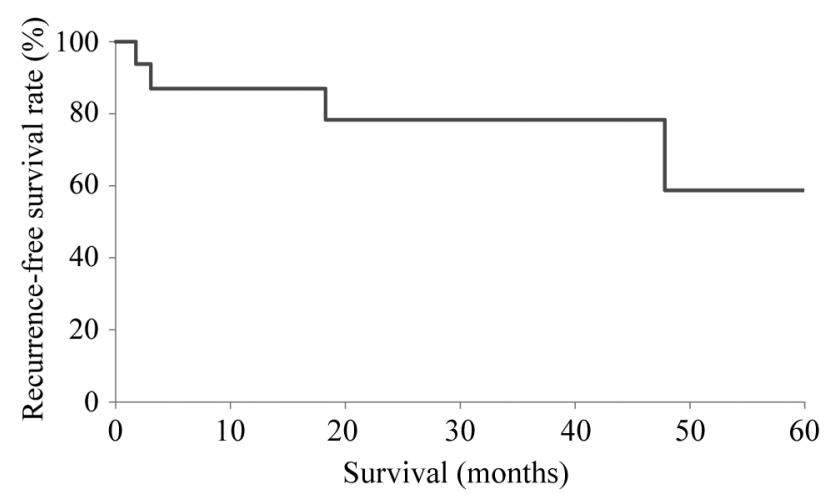

$\mathrm{B}$

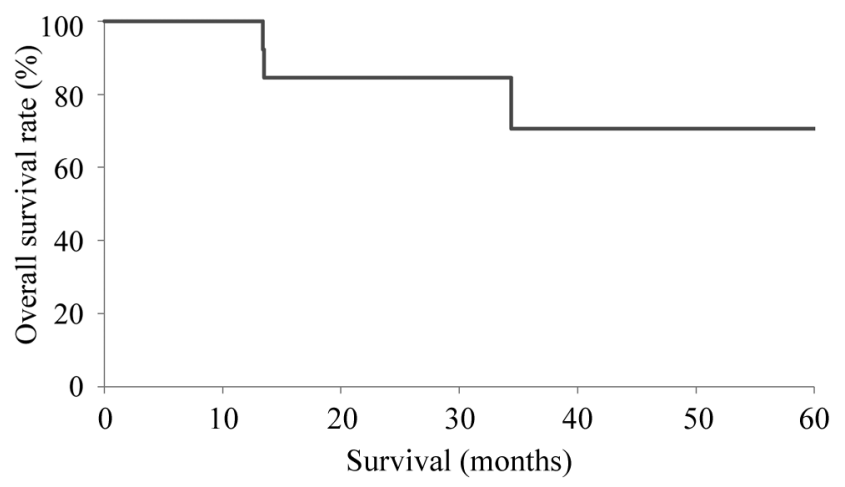

Figure 3. Long-term outcomes of patients with gallbladder carcinoma $(n=20)$. A: recurrence-free survival. The 1-, 3-, and 5-year rates were 87\%, $78.3 \%$, and $58.8 \%$, respectively. B: Overall survival. The 1-, 3-, and 5-year rates were 100\%, 70.5\%, and 70.5\%, respectively.

Table II. Data of the patients pathologically diagnosed with gallbladder cancer.

\begin{tabular}{|c|c|c|c|c|c|c|c|c|}
\hline ID no. & Side & $\begin{array}{c}\text { Pathological } \\
\text { depth }\end{array}$ & $\begin{array}{c}\text { Pathological } \\
\text { vascular } \\
\text { invasion }\end{array}$ & $\begin{array}{c}\text { Pathological } \\
\text { N-stage }\end{array}$ & $\begin{array}{l}\text { Recurrence } \\
\text { location } \\
\text { (primary) }\end{array}$ & $\begin{array}{l}\text { RFS, } \\
\text { months }\end{array}$ & $\begin{array}{c}\text { OS, } \\
\text { months }\end{array}$ & $\begin{array}{l}\text { Outcome at } \\
\text { end of study }\end{array}$ \\
\hline 1 & Hepatic & Mucosa & ly0, v0 & 0 & - & 68 & 68 & Alive \\
\hline 2 & Hepatic & Mucosa & ly0, v0 & 0 & - & 18 & 18 & Alive \\
\hline 3 & Peritoneal & Mucosa & ly0, v0 & 0 & - & 1 & 1 & Alive \\
\hline 4 & Peritoneal & MP & ly0, v0 & 0 & - & 26 & 26 & Alive \\
\hline 5 & Hepatic & MP & ly0, v0 & 0 & - & 15 & 15 & Alive \\
\hline 6 & Hepatic & MP & ly0, v0 & 0 & - & 6 & 6 & Alive \\
\hline 7 & Hepatic & MP & ly0, v0 & 0 & - & 2 & 2 & Alive \\
\hline 8 & Peritoneal & MP & ly0, v0 & 0 & - & 1 & 1 & Alive \\
\hline 9 & Hepatic & SS & ly0, v0 & 0 & - & 95 & 95 & Alive \\
\hline 10 & Peritoneal & SS & ly1, v0 & 0 & - & 48 & 48 & Alive \\
\hline 11 & Hepatic & SS & ly0, v0 & 0 & - & 7 & 7 & Alive \\
\hline 12 & Hepatic & SS & ly0, v0 & 0 & - & 6 & 6 & Alive \\
\hline 13 & Peritoneal & SS & ly0, v0 & 0 & - & 1 & 1 & Alive \\
\hline 14 & Peritoneal* & SS & ly0, v1 & 1 & - & 2 & 2 & Alive \\
\hline 15 & Hepatic & T3 (liver) & ly1, v1 & 0 & - & 21 & 21 & Alive \\
\hline 16 & Hepatic & MP & ly0, v0 & 0 & - & 43 & 43 & Died from other cause \\
\hline 17 & Hepatic* & SS & ly0, v0 & 1 & Liver $(4 a)$ & 48 & 80 & Cancer-related death \\
\hline 18 & Hepatic* & SS & ly0, v0 & 1 & Lymph node around SMA & 3 & 14 & Cancer-related death \\
\hline 19 & Hepatic & SS & ly1, v2 & 0 & Liver (S8)/lymph node & 2 & 14 & Cancer-related death \\
\hline 20 & Hepatic & SS & ly3, v0 & 0 & Liver (multiple) & 18 & 35 & Cancer-related death \\
\hline
\end{tabular}

*Converted to laparotomy due to positive lymph nodes. MP: Muscularis propria; OS: overall survival; RFS: recurrence-free survival; SM: superior mesenteric artery; SS: subserosa.

controversial $(24,25)$. A previous study reported that pT2 gallbladder cancer requires hepatectomy to secure safe margins on the liver side (referred to as "gallbladder bed resection") and as prophylactic resection to prevent hepatic metastasis (referred to as "segment $4 \mathrm{~b}$ and 5 resection") (26). The progression of gallbladder cancer to the liver occurs by intrahepatic lymphatic invasion via the Glissonean sheath or by direct invasion $(27,28)$. Previous research has shown no significant differences in the outcome of gallbladder bed resection versus resection of segments $4 \mathrm{~b}$ and 5 for $\mathrm{T} 2$ gallbladder cancer $(26,29)$. Based on the abovementioned findings, we adopted LGBR to achieve a negative margin on the hepatic side in the case of open surgery. The perioperative results show that our surgical strategy for gallbladder tumours is safe and feasible, regardless of whether the tumour is benign or malignant. 
Established procedures for gallbladder cancer removal and technical improvements and advances in instruments can resolve the reported issues associated with laparoscopic surgery for gallbladder cancer, such as insufficient excision of the cancer (2) and bile spillage due to intraoperative gallbladder injury $(3,4)$. Regarding potential port site recurrence, a previous study reported no differences in the occurrence of port site/wound or peritoneal metastases and survival outcomes between patients undergoing laparoscopic versus open surgery (30). No port site recurrence or peritoneal dissemination was detected in the present study.

In the present study, we analysed the long-term outcomes of gallbladder cancer and obtained 1-, 3-, and 5-year RFS rates of $87 \%, 78.3 \%$ and $58.8 \%$, respectively, and 1-, 3-, and 5 -year OS rates of $100 \%, 70.5 \%$ and $70.5 \%$, respectively. Several previous studies have reported that laparoscopic surgery obtains a favourable long-term outcome (9) with similar recurrence and survival rates to open surgery (10, 11). However, the small sample sizes in previous studies have prevented a comparison of the oncological outcome between laparoscopic and open surgery. In our series of patients with gallbladder cancer, we focused on the incidence of recurrence. Among the four patients with recurrence, the primary recurrence locations were the liver and lymph nodes. Although the number of patients was limited, our results suggest that the long-term outcome of gallbladder cancer may be improved not only through local control by resection but also through the control of distant metastatic lesions after resection. Therefore, effective adjuvant chemotherapy is required to improve the long-term outcome, although the optimal regimen has not yet been established in Japan (1). The British phase III BILCAP study reported a significant difference in OS between the capecitabine and observation groups in a per-protocol analysis (31). Based on this result, the American Society of Clinical Oncology and the National Comprehensive Cancer Network recommend offering adjuvant capecitabine chemotherapy to patients with resected biliary tract cancer $(32,33)$. However, adjuvant chemotherapy may not be feasible for patients who have undergone surgery for biliary tract cancer for the following three reasons (34). Firstly, surgical treatment for biliary tract cancer requires invasive procedures with high morbidity and mortality rates. Therefore, many patients do not fully recover after surgery, precluding adjuvant therapy, and do not experience a survival benefit from adjuvant therapy. Secondly, there is a long interval between surgical treatment and the commencement of adjuvant chemotherapy (35). Thirdly, the completion rate or dose intensity of adjuvant chemotherapy after biliary tract cancer resection is low. To overcome these problems, our surgical strategy may have a fundamental advantage due to its minimal invasiveness.

The present study has limitations. Firstly, it was based on a single-centre review of a limited number of patients.
Secondly, there is the potential for selection bias because of the retrospective design. Further comparative studies are needed to assess the oncological safety of laparoscopic surgery for gallbladder cancer.

In conclusion, we analysed the feasibility and safety of laparoscopic gallbladder resection for gallbladder tumours. Control of distant metastatic lesions after resection was considered to improve the long-term outcome of gallbladder cancer. A minimally invasive surgical approach may enable the early start of adjuvant chemotherapy for gallbladder cancer.

\section{Conflicts of Interest}

The Authors declare no conflicts of interest in association with the present study.

\section{Authors' Contributions}

HI and TA: Study design. HI, TA, TT, HM, TH, AS and MH: Data collection. HI, TA, TT: Data analysis and interpretation. TA, TT, HM, TH, AS, MH and SE: Contribution of important reagents. HI, TA and SE: Article writing.

\section{References}

1 Nagino M, Hirano S, Yoshitomi H, Aoki T, Uesaka K, Unno M, Ebata T, Konishi M, Sano K, Shimada K, Shimizu H, Higuchi R, Wakai T, Isayama H, Okusaka T, Tsuyuguchi T, Hirooka Y, Furuse J, Maguchi H, Suzuki K, Yamazaki H, Kijima H, Yanagisawa A, Yoshida M, Yokoyama Y, Mizuno T and Endo I: Clinical practice guidelines for the management of biliary tract cancers 2019: The 3rd English edition. J Hepatobiliary Pancreat Sci 28(1): 26-54, 2021. PMID: 33259690. DOI: 10.1002/jhbp. 870

2 Ome Y, Hashida K, Yokota M, Nagahisa Y, Okabe M and Kawamoto K: Laparoscopic approach to suspected T1 and T2 gallbladder carcinoma. World J Gastroenterol 23(14): 25562565, 2017. PMID: 28465640. DOI: 10.3748/wjg.v23.i14.2556

3 Wakai T, Shirai Y, Yokoyama N, Nagakura S, Watanabe H and Hatakeyama K: Early gallbladder carcinoma does not warrant radical resection. Br J Surg 88(5): 675-678, 2001. PMID: 11350438. DOI: 10.1046/j.1365-2168.2001.01749.x

4 Ouchi K, Mikuni J, Kakugawa Y and Organizing Committee, The 30th Annual Congress of the Japanese Society of Biliary Surgery: Laparoscopic cholecystectomy for gallbladder carcinoma: results of a Japanese survey of 498 patients. J Hepatobiliary Pancreat Surg 9(2): 256-260, 2002. PMID: 12140616. DOI: $10.1007 / \mathrm{s} 005340200028$

5 Z'graggen K, Birrer S, Maurer CA, Wehrli H, Klaiber C and Baer HU: Incidence of port site recurrence after laparoscopic cholecystectomy for preoperatively unsuspected gallbladder carcinoma. Surgery 124(5): 831-838, 1998. PMID: 9823395.

6 Lundberg $\mathrm{O}$ and Kristoffersson A: Port site metastases from gallbladder cancer after laparoscopic cholecystectomy. Results of a Swedish survey and review of published reports. Eur J Surg 165(3): 215-222, 1999. PMID: 10231654. DOI: 10.1080/ 110241599750007072

7 Kokudo N, Makuuchi M, Natori T, Sakamoto Y, Yamamoto J, Seki M, Noie T, Sugawara Y, Imamura H, Asahara S and Ikari 
T: Strategies for surgical treatment of gallbladder carcinoma based on information available before resection. Arch Surg 138(7): 741-50; discussion 750, 2003. PMID: 12860755. DOI: 10.1001/archsurg.138.7.741

8 Sadamoto Y, Kubo H, Harada N, Tanaka M, Eguchi T and Nawata H: Preoperative diagnosis and staging of gallbladder carcinoma by EUS. Gastrointest Endosc 58(4): 536-541, 2003. PMID: 14520286. DOI: 10.1067/s0016-5107(03)01961-8

9 Yoon YS, Han HS, Cho JY, Choi Y, Lee W, Jang JY and Choi H: Is laparoscopy contraindicated for gallbladder cancer? A 10-year prospective cohort study. J Am Coll Surg 221(4): 847-853, 2015 PMID: 26272017. DOI: 10.1016/j.jamcollsurg.2015.07.010

10 Itano O, Oshima G, Minagawa T, Shinoda M, Kitago M, Abe Y, Hibi T, Yagi H, Ikoma N, Aiko S, Kawaida M, Masugi Y, Kameyama K, Sakamoto M and Kitagawa Y: Novel strategy for laparoscopic treatment of pT2 gallbladder carcinoma. Surg Endosc 29(12): 3600-3607, 2015. PMID: 25740638. DOI: 10.1007/s00464-015-4116-y

11 Agarwal AK, Javed A, Kalayarasan R and Sakhuja P: Minimally invasive versus the conventional open surgical approach of a radical cholecystectomy for gallbladder cancer: a retrospective comparative study. HPB (Oxford) 17(6): 536-541, 2015. PMID: 25727091. DOI: $10.1111 / \mathrm{hpb} .12406$

12 Shirobe T and Maruyama S: Laparoscopic radical cholecystectomy with lymph node dissection for gallbladder carcinoma. Surg Endosc 29(8): 2244-2250, 2015. PMID: 25303926. DOI: 10.1007/s00464-014-3932-9

13 Jang JY, Heo JS, Han Y, Chang J, Kim JR, Kim H, Kwon W, Kim SW, Choi SH, Choi DW, Lee K, Jang KT, Han SS and Park SJ: Impact of type of surgery on survival outcome in patients with early gallbladder cancer in the era of minimally invasive surgery: Oncologic safety of laparoscopic surgery. Medicine (Baltimore) 95(22): e3675, 2016. PMID: 27258495. DOI: 10.1097/MD.0000000000003675

14 Kanda Y: Investigation of the freely available easy-to-use software 'EZR' for medical statistics. Bone Marrow Transplant 48(3): 452458, 2013. PMID: 23208313. DOI: 10.1038/bmt.2012.244

15 Kubota K, Bandai $Y$, Noie $T$, Ishizaki $Y$, Teruya $M$ and Makuuchi M: How should polypoid lesions of the gallbladder be treated in the era of laparoscopic cholecystectomy? Surgery 117(5): 481-487, 1995. PMID: 7740417. DOI: 10.1016/s00396060(05)80245-4

16 Park JK, Yoon YB, Kim YT, Ryu JK, Yoon WJ, Lee SH, Yu SJ, Kang HY, Lee JY and Park MJ: Management strategies for gallbladder polyps: is it possible to predict malignant gallbladder polyps? Gut Liver 2(2): 88-94, 2008. PMID: 20485616. DOI: 10.5009/gnl.2008.2.2.88

17 Cha BH, Hwang JH, Lee SH, Kim JE, Cho JY, Kim H and Kim SY: Pre-operative factors that can predict neoplastic polypoid lesions of the gallbladder. World J Gastroenterol 17(17): 22162222, 2011. PMID: 21633532. DOI: 10.3748/wjg.v17.i17.2216

18 Jang JY, Kim SW, Lee SE, Hwang DW, Kim EJ, Lee JY, Kim SJ, Ryu JK and Kim YT: Differential diagnostic and staging accuracies of high resolution ultrasonography, endoscopic ultrasonography, and multidetector computed tomography for gallbladder polypoid lesions and gallbladder cancer. Ann Surg 250(6): 943-949, 2009. PMID: 19855259. DOI: 10.1097/SLA.0b013e3181b5d5fc

19 Tsukada K, Hatakeyama K, Kurosaki I, Uchida K, Shirai Y, Muto $\mathrm{T}$ and Yoshida $\mathrm{K}$ : Outcome of radical surgery for carcinoma of the gallbladder according to the TNM stage.
Surgery 120(5): 816-821, 1996. PMID: 8909516. DOI: 10.1016/ s0039-6060(96)80089-4

20 Shimizu Y, Ohtsuka M, Ito H, Kimura F, Shimizu H, Togawa A, Yoshidome H, Kato A and Miyazaki M: Should the extrahepatic bile duct be resected for locally advanced gallbladder cancer? Surgery 136(5): 1012-7; discussion 1018, 2004. PMID: 15523394. DOI: $10.1016 /$ j.surg.2004.04.032

21 Suzuki S, Yokoi Y, Kurachi K, Inaba K, Ota S, Azuma M, Konno $\mathrm{H}$, Baba S and Nakamura S: Appraisal of surgical treatment for pT2 gallbladder carcinomas. World J Surg 28(2): 160-165, 2004. PMID: 14708053. DOI: 10.1007/s00268-003-7080-y

22 Sakamoto Y, Kosuge T, Shimada K, Sano T, Hibi T, Yamamoto $\mathrm{J}$, Takayama $\mathrm{T}$ and Makuuchi $\mathrm{M}$ : Clinical significance of extrahepatic bile duct resection for advanced gallbladder cancer. J Surg Oncol 94(4): 298-306, 2006. PMID: 16917876. DOI: $10.1002 /$ jso. 20585

23 Sakamoto Y, Sano T, Shimada K, Kosuge T, Kimata Y, Sakuraba $\mathrm{M}$, Yamamoto $\mathrm{J}$ and Ojima $\mathrm{H}$ : Clinical significance of reconstruction of the right hepatic artery for biliary malignancy. Langenbecks Arch Surg 391(3): 203-208, 2006. PMID: 16525853. DOI: 10.1007/s00423-006-0026-8

24 Castro CM, Santibañez SP, Rivas TC and Cassis NJ: Totally laparoscopic radical resection of gallbladder cancer: technical aspects and long-term results. World J Surg 42(8): 2592-2598, 2018. PMID: 29520484. DOI: 10.1007/s00268-018-4490-4

25 Kim WJ, Lim TW, Park PJ, Choi SB and Kim WB: Safety and feasibility of pure laparoscopic extended cholecystectomy: comparison with the open technique in a propensity analysis at a single center. Surg Endosc 35(11): 6166-6172, 2021. PMID: 33409594. DOI: $10.1007 / \mathrm{s} 00464-020-08112-3$

26 Horiguchi A, Miyakawa S, Ishihara S, Miyazaki M, Ohtsuka M, Shimizu H, Sano K, Miura F, Ohta T, Kayahara M, Nagino M, Igami T, Hirano S, Yamaue H, Tani M, Yamamoto M, Ota T, Shimada M, Morine Y, Kinoshita H, Yasunaga M and Takada T: Gallbladder bed resection or hepatectomy of segments $4 \mathrm{a}$ and 5 for pT2 gallbladder carcinoma: analysis of Japanese registration cases by the study group for biliary surgery of the Japanese Society of Hepato-Biliary-Pancreatic Surgery. J Hepatobiliary Pancreat Sci 20(5): 518-524, 2013. PMID: 23430053. DOI: 10.1007/s00534-012-0584-9

27 Shirai Y, Tsukada K, Ohtani T, Watanabe H and Hatakeyama K: Hepatic metastases from carcinoma of the gallbladder. Cancer 75(8): 2063-2068, 1995. PMID: 7697595. DOI: 10.1002/10970142(19950415)75:8<2063::aid-cncr2820750806>3.0.co;2-s

28 Wakai T, Shirai Y, Sakata J, Nagahashi M, Ajioka Y and Hatakeyama K: Mode of hepatic spread from gallbladder carcinoma: an immunohistochemical analysis of 42 hepatectomized specimens. Am J Surg Pathol 34(1): 65-74, 2010. PMID: 19956061. DOI: 10.1097/PAS.0b013e3181c467d4

29 Higuchi R, Ota T, Araida T, Kajiyama H, Yazawa T, Furukawa $\mathrm{T}$, Yoshikawa T, Takasaki $\mathrm{K}$ and Yamamoto $\mathrm{M}$ : Surgical approaches to advanced gallbladder cancer : a 40-year singleinstitution study of prognostic factors and resectability. Ann Surg Oncol 21(13): 4308-4316, 2014. PMID: 25023547. DOI: 10.1245/s10434-014-3885-1

30 Han HS, Yoon YS, Agarwal AK, Belli G, Itano O, Gumbs AA, Yoon DS, Kang CM, Lee SE, Wakai $\mathrm{T}$ and Troisi RI: Laparoscopic surgery for gallbladder cancer: an expert consensus statement. Dig Surg 36(1): 1-6, 2019. PMID: 29339660. DOI: $10.1159 / 000486207$ 
31 Primrose JN, Fox RP, Palmer DH, Malik HZ, Prasad R, Mirza D, Anthony A, Corrie P, Falk S, Finch-Jones M, Wasan H, Ross P, Wall L, Wadsley J, Evans JTR, Stocken D, Praseedom R, Ma YT, Davidson B, Neoptolemos JP, Iveson T, Raftery J, Zhu S, Cunningham D, Garden OJ, Stubbs C, Valle JW, Bridgewater J and BILCAP study group: Capecitabine compared with observation in resected biliary tract cancer (BILCAP): a randomised, controlled, multicentre, phase 3 study. Lancet Oncol 20(5): 663-673, 2019. PMID: 30922733. DOI: 10.1016/S14702045(18)30915-X

32 Shroff RT, Kennedy EB, Bachini M, Bekaii-Saab T, Crane C, Edeline J, El-Khoueiry A, Feng M, Katz MHG, Primrose J, Soares HP, Valle J and Maithel SK: Adjuvant therapy for resected biliary tract cancer: ASCO clinical practice guideline. J Clin Oncol 37(12): 1015-1027, 2019. PMID: 30856044. DOI: 10.1200/JCO.18.02178

33 Benson AB 3rd, Abrams TA, Ben-Josef E, Bloomston PM, Botha JF, Clary BM, Covey A, Curley SA, D'Angelica MI, Davila R, Ensminger WD, Gibbs JF, Laheru D, Malafa MP, Marrero J, Meranze SG, Mulvihill SJ, Park JO, Posey JA, Sachdev J, Salem R, Sigurdson ER, Sofocleous C, Vauthey JN, Venook AP, Goff LW, Yen $\mathrm{Y}$ and Zhu AX: NCCN clinical practice guidelines in oncology: hepatobiliary cancers. J Natl Compr Canc Netw 7(4): 350-391, 2009. PMID: 19406039. DOI: 10.6004/jnccn.2009.0027
34 Nara S, Esaki M, Ban D, Takamoto T, Shimada K, Ioka T, Okusaka T, Ishii $\mathrm{H}$ and Furuse $\mathrm{J}$ : Adjuvant and neoadjuvant therapy for biliary tract cancer: a review of clinical trials. Jpn J Clin Oncol 50(12): 1353-1363, 2020. PMID: 33037430. DOI: $10.1093 / \mathrm{jjco} / \mathrm{hyaa} 170$

35 Kobayashi S, Nagano H, Tomokuni A, Gotoh K, Sakai D, Hatano E, Seo S, Terajima H, Uchida Y, Ajiki T, Satake H, Kamei K, Tohyama T, Hirose T, Ikai I, Morita S, Ioka T and Kansai HepatoBiliary Oncology (KHBO) Group: A prospective, randomized phase II study of adjuvant gemcitabine versus S-1 after major hepatectomy for biliary tract cancer (KHBO 1208): Kansai HepatoBiliary Oncology group. Ann Surg 270(2): 230-237, 2019. PMID: 30339627. DOI: $10.1097 /$ SLA.0000000000002865
Received November 2, 2021

Revised December 3, 2021

Accepted December 8, 2021 